\title{
Amyloid $\beta$-Induced Neuronal Hyperexcitability Triggers Progressive Epilepsy
}

\author{
Rimante Minkeviciene, ${ }^{1 \star}$ Sylvain Rheims,${ }^{3 \star}$ Marton B. Dobszay, ${ }^{5 *}$ Misha Zilberter, ${ }^{5}$ Jarmo Hartikainen, ${ }^{1}$ Lívia Fülöp, ${ }^{6}$ \\ Botond Penke, ${ }^{7}$ Yuri Zilberter, ${ }^{4,5}$ Tibor Harkany, ${ }^{5,8}$ Asla Pitkänen, ${ }^{1,2}$ and Heikki Tanila ${ }^{1,2}$ \\ ${ }^{1}$ A. I. Virtanen Institute, University of Kuopio, and ${ }^{2}$ Department of Neurology, Kuopio University Hospital, FIN-70211 Kuopio, Finland, ${ }^{3}$ Faculté de \\ Sciences de Luminy, Aix Marseille Université, and ${ }^{4}$ Institut National de la Santé et de la Recherche Médicale, Institut de Neurobiologie de la Méditerranée \\ U901, F-13000 Marseille, France, ${ }^{5}$ Division of Molecular Neurobiology, Department of Medical Biochemistry and Biophysics, Karolinska Institutet, \\ Stockholm, S-17177 Stockholm, Sweden, ${ }^{6}$ Department of Medical Chemistry and 7 Supramolecular and Nanostructured Materials Research Group of the \\ Hungarian Academy of Science, University of Szeged, H-6720 Szeged, Hungary, ${ }^{8}$ Institute of Medical Sciences, College of Life Sciences \& Medicine, \\ University of Aberdeen, Aberdeen, AB25 2ZD, United Kingdom
}

\begin{abstract}
Alzheimer's disease is associated with an increased risk of unprovoked seizures. However, the underlying mechanisms of seizure induction remain elusive. Here, we performed video-EEG recordings in mice carrying mutant human APPswe and PS1dE9 genes (APdE9 mice) and their wild-type littermates to determine the prevalence of unprovoked seizures. In two recording episodes at the onset of amyloid $\beta$ (A $\beta$ ) pathogenesis (3 and 4.5 months of age), at least one unprovoked seizure was detected in $65 \%$ of $A P d E 9$ mice, of which $46 \%$ had multiple seizures and $38 \%$ had a generalized seizure. None of the wild-type mice had seizures. In a subset of $A P d E 9$ mice, seizure phenotype was associated with a loss of calbindin-D28k immunoreactivity in dentate granular cells and ectopic expression of neuropeptide $\mathrm{Y}$ in mossy fibers. In APdE9 mice, persistently decreased resting membrane potential in neocortical layer $2 / 3$ pyramidal cells and dentate granule cells underpinned increased network excitability as identified by patch-clamp electrophysiology. At stimulus strengths evoking single-component EPSPs in wild-type littermates, APdE9 mice exhibited decreased action potential threshold and burst firing of pyramidal cells. Bath application ( $1 \mathrm{~h}$ ) of $\mathrm{A} \beta 1-42$ or A $\beta 25-35$ (proto-)fibrils but not oligomers induced significant membrane depolarization of pyramidal cells and increased the activity of excitatory cell populations as measured by extracellular field recordings in the juvenile rodent brain, confirming the pathogenic significance of bath-applied A $\beta$ (proto-)fibrils. Overall, these data identify fibrillar A $\beta$ as a pathogenic entity powerfully altering neuronal membrane properties such that hyperexcitability of pyramidal cells culminates in epileptiform activity.
\end{abstract}

\section{Introduction}

Prevalence of unprovoked seizures in Alzheimer's disease (AD) is significantly higher than in age-matched control populations (Hauser et al., 1986; Mendez et al., 1994; Hesdorffer et al., 1996; Amatniek et al., 2006; Lozsadi and Larner, 2006). The risk of epileptic seizures is particularly high in AD patients with earlyonset dementia and during early stages of the disease, reaching an 87 -fold increase in seizure incidence compared with an agematched reference population (Amatniek et al., 2006). Whether this comorbidity is just a coincidence because of high prevalence

Received 0ct. 29, 2008; revised Jan. 5, 2009; accepted Feb. 8, 2009.

This work was supported by the Finnish Cultural Foundation (R.M.), Northern-Savonia Regional Funds (R.M.), Institut National de la Santé et de la Recherche Médicale (INSERM; Y.Z. is the recipient of a Contrat d'interface between INSERM and (entre Hospitalier Universitaire Necker Paris, France), the Swedish Medical Research Council (T.H.), the EMBO Young Investigator Programme (T.H.), the Alzheimer's Association (T.H.), the Alzheimer's Research Trust UK (T.H.), the European Union Seventh Framework Program (HEALTH-F2-2007-201159; H.T., T.H., Y.Z., B.P. and L.F.), the Academy of Finland (A.P.), and the Sigrid Juselius Foundation (A.P.). We thank Dr. D. Borchelt and J. Jankowsky for APdE9 colony founders and Merja Lukkari for skillful technical assistance in histology.

${ }^{*}$ R.M., S.R., and M.B.D. contributed equally to this work.

Correspondence should be addressed to Dr. Heikki Tanila, Department of Neurobiology, A. I. Virtanen Institute, University of Kuopio, P.0. Box 1627, Neulaniementie 2, FIN-70211 Kuopio, Finland. E-mail: Heikki.Tanila@uku.fi. DOI:10.1523/JNEUROSCI.5215-08.2009

Copyright $\odot 2009$ Society for Neuroscience $\quad$ 0270-6474/09/293453-10\$15.00/0 of both $\mathrm{AD}$ and epilepsy in the elderly over 65 years of age (Breteler et al., 1992; Olafsson et al., 2005) or whether AD pathology makes the brain particularly susceptible to seizure generation remains elusive.

Transgenic mice overexpressing mutant amyloid precursor protein (APP) and thereby producing excessive amounts of amyloid $\beta(\mathrm{A} \beta)$ are critical to understand cellular principles of $\mathrm{AD}$ pathogenesis. These mice manifest several AD-like abnormalities during aging including $\mathrm{A} \beta$ plaques, neurite dystrophy, structural synaptic deficits, reduced synaptic plasticity, and impaired learning and memory (Games et al., 1995; Price et al., 1998; Götz et al., 2004; Kobayashi and Chen, 2005). A prominent observation in various strains of mice with age-related $A \beta$ overload is their increased mortality. However, this has attracted only sporadic attention to date. $\mathrm{A} \beta$-overexpressing mice have a normal lifespan with occasional reports noting sudden death of unknown origin, even at remarkably young ages (Hsiao et al., 1995; Leissring et al., 2003; Chin et al., 2004). Our colony of APdE9 mice carrying human APP with Swedish double mutation (APPswe) cointegrated with human preselinin-1 with exon 9 deletion (PS1dE9) (Jankowsky et al., 2004) is plagued with 10-15\% mortality, which does not associate with any gross postmortem pathology. Sudden 
deaths in these mice may occur at any age but peak around 3-4 months of age when the first plaques appear in the cortex and the hippocampus (Garcia-Alloza et al., 2006; Shemer et al., 2006). A causal link between $\mathrm{A} \beta$ accumulation and epileptogenesis is strengthened by a recent study reporting the presence of cortical and hippocampal nonconvulsive seizures and coincident morphological and functional alterations in three different $A P P$ transgenic mouse lines (Palop et al., 2007). These alterations were similar to those induced by excitotoxic stimuli and likely counteracted an initial neuronal overexcitability in corticolimbic neuronal networks (Palop et al., 2007; Busche et al., 2008). Here, we significantly extend these findings by showing high prevalence of epileptic seizures in APdE9 transgenic mice in systematic longterm video-EEG recordings and by demonstrating that both endogenous overproduction and external application of structurally ordered $A \beta$ aggregates enhances excitability of layer $2 / 3$ (L2/3) pyramidal and dentate granule cells (GCs) through sustained resting membrane potential $\left(V_{\mathrm{R}}\right)$ depolarization.

\section{Materials and Methods \\ Animals}

Adult male heterozygous APdE9 mice and their nontransgenic littermates (later referred to as wild-type mice) were used in this study. APdE9 colony founders were obtained from D. Borchelt and J. Jankowsky (Johns Hopkins University, Baltimore, MD). This strain expresses mouse APP695 harboring a human A $\beta$ domain and mutations $\mathrm{K} 595 \mathrm{~N}$ and M596L linked to Swedish familial AD pedigrees, and human PS1-dE9 (deletion of exon 9) vectors controlled by independent mouse prion protein promoter elements. The two transgenes cointegrate and cosegregate as a single locus (Jankowsky et al., 2004). Although this line was originally maintained on a hybrid background, mice at the University of Kuopio were backcrossed for nine generations to C57BL/6J mice. Notably, the time course of $\mathrm{A} \beta$ pathology is similar in the mouse line kept on a $\mathrm{C} 57 \mathrm{BL} /$ $6 \mathrm{~J} \times \mathrm{C} 3 \mathrm{H}$ hybrid background (Garcia-Alloza et al., 2006) as our backcrossed C57BL/6J line (Shemer et al., 2006; Minkeviciene et al., 2008). Throughout the experiments, animals were housed individually in cages in a controlled environment (temperature, $21 \pm 1^{\circ} \mathrm{C}$; humidity, $50 \pm$ 10\%; light period, 7:00 A.M. to 7:00 P.M.) and had ad libitum access to food and water. Experiments were conducted in accordance with the European Communities Directive (86/609/EEC), and respective Finnish, Swedish, French Public Health Service, and INSERM (Institut National de la Santé et de la Recherche Médicale) guidelines on the handling and use of laboratory animals; and approved by the State Provincial Office of Eastern Finland or Stockholms Norra Djuretiska Nämnd (N28/05, N36/05).

\section{Video-EEG recordings}

Implantation of cortical EEG electrodes. Twenty APdE9 mice and 10 nontransgenic littermates were implanted with chronic electrodes for videoEEG recordings. At the age of 2.5 months (9-11 weeks), mice were implanted with four stainless steel screw electrodes under pentobarbiturate/ chloral hydrate anesthesia (each $70 \mathrm{mg} / \mathrm{kg}$, i.p.). Two electrodes were secured to the skull bilaterally above the frontal cortex, whereas the other two were positioned bilaterally on the occipital bone over the cerebellum to serve as reference and ground electrodes. A miniature connector (Plastics One) was fixed to the screws and skull with acrylic cement. The animals were then allowed to recover for at least 1 week before recordings commenced.

Behavioral and EEG monitoring of spontaneous seizures. At the age of 3 months (11-13 weeks), mice were subjected to continuous video-EEG monitoring for 2 weeks to detect the occurrence of spontaneous seizures. Another 1 week period of continuous video-EEG recording was performed at the age of 4.5 months (17-19 weeks) to determine probable progressive increases in seizure occurrence and frequency. Mice were placed in perpex cages where they could move freely (one mouse per cage). Electrical brain activity was monitored using a Nervus EEG Recording System connected to a Nervus Magnus 32/8 Amplifier at a sampling rate of $256 \mathrm{~Hz}$ and filtered (high-pass filter, $0.3 \mathrm{~Hz}$ cutoff; low-pass filter, $100 \mathrm{~Hz}$ ). The behavior of the animals was recorded using a WVBP330/GE Video Camera (Panasonic) that was positioned in front of the cages and connected to a SVT-N72P Time Lapse VCR (Sony) and a PVM-145E Video Monitor (Sony). WFL-II/LED15W infrared light (Videor Technical) was used during the dark periods to allow continuous video monitoring. A wide-angle lens permitted simultaneous videotaping of up to eight animals.

Analysis of video-EEG. Each digitized EEG file was screened visually to detect seizure activity. Automatic seizure identification algorithms were not used because they only detect $\sim 80 \%$ of electrographic seizures. If an electrographic seizure was observed, its behavioral severity was analyzed from the corresponding video recording. An electrographic seizure was defined as high-amplitude rhythmic discharges that clearly represented a new pattern of tracing (repetitive spikes, spike-and-wave discharges, and slow waves) and lasted for $\geq 5 \mathrm{~s}$. Epileptic events occurring with an interval $<5 \mathrm{~s}$ without the EEG returning to baseline were defined as belonging to the same seizure. Spontaneous spikes were defined as sharp $(<50 \mathrm{~ms})$ positive or negative deflections with amplitudes exceeding twice the baseline EEG. The severity of behavioral seizures was scored according to a slightly modified Racine's scale (Racine 1972): score 0, electrographic seizure without any detectable motor manifestation; score 1 , mouth and face clonus and head nodding; score 2, clonic jerks of one forelimb; score 3, bilateral forelimb clonus; score 4, forelimb clonus and rearing; score 5, forelimb clonus with rearing and falling. Behavioral seizures were further classified into two categories: partial seizures (stages $0-2$ ) or secondary generalized seizures (stages 3-5).

For the epilepsy diagnosis, we adopted the recent terminology proposed by the International League Against Epilepsy and the International Bureau for Epilepsy (Fisher et al., 2005). Accordingly, epilepsy diagnosis requires one epileptic seizure in association with an enduring disturbance of the brain capable of giving rise to subsequent seizures.

\section{Histochemistry and morphometry}

After the final video-EEG recording at the age of 5 months (20-23 weeks), mice were deeply anesthetized and perfused transcardially according to Timm's fixation as described previously (Sloviter, 1982). Brains were removed from the skull, postfixed in buffered $4 \%$ paraformaldehyde for $4 \mathrm{~h}$, and subsequently cryoprotected in a solution composed of $20 \%$ glycerol in $0.02 \mathrm{M} \mathrm{K-PBS,} \mathrm{pH} \mathrm{7.4,} \mathrm{for} 24 \mathrm{~h}$ at $4^{\circ} \mathrm{C}$. Brains were then blocked, frozen on dry ice, and stored at $-70^{\circ} \mathrm{C}$ until sectioning. Coronal sections were cut ( $25 \mu \mathrm{m}$, one-in-six series) on a freezing sliding microtome and stored in a cryoprotectant tissue-collecting solution composed of $30 \%$ ethylene glycol and $25 \%$ glycerol in $0.05 \mathrm{M} \mathrm{Na}$ phosphate buffer at $-20^{\circ} \mathrm{C}$ until histochemical processing.

Adjacent series of sections were used for thionin (Nissl), Timm, A $\beta$, calbindin-D28k, and neuropeptide Y (NPY) stainings. To identify cytoarchitectonic boundaries of the various brain areas, the first series of sections was stained for thionin. The second series of sections was stained by the Timm sulfide/silver method (Sloviter, 1982; Nissinen et al., 2001) to visualize sprouting of GC axons (mossy fibers). The third series was processed for visualizing $\mathrm{A} \beta$ (mouse anti-human $\mathrm{A} \beta 4-10$ (WO-2); Genetics) as described previously (Oksman et al., 2006). Sections were exposed to biotinylated goat anti-mouse IgG as the secondary antibody (Sigma), and immunoreactivity was visualized with $\mathrm{H}_{2} \mathrm{O}_{2}$ and nickelenhanced 3,3'-diaminobenzidine (Ni-DAB). The above protocols were performed in all except one APdE9 mouse that had died before perfusion ( $A P d E 9, n=19$; controls, $n=10$ ). In addition, select sections from seven wild-type and seven $A P d E 9$ mice with no seizures and seven $A P d E 9$ mice with seizures were immunolabeled for calbindin-D28k and NPY as described previously (Sorvari et al., 1996) with mouse anti-calbindin-D28k (1:50,000; Swant) and rabbit anti-NPY (1:20,000; T4070; Peninsula Laboratories) primary antibodies, respectively. Horse anti-mouse whole IgG (1:200; Swant) and biotinylated goat anti-rabbit IgG (1:200; BA-1000; Vector Laboratories) were applied as secondary antibodies, and immunoreactivity was revealed by a chromogenic DAB reaction.

Mossy fiber sprouting was analyzed in 14 adjacent Timm-stained coronal sections (one-in-six series of 25 - $\mu$ m-thick sections; intersection interval, $150 \mu \mathrm{m}$ ) throughout the septotemporal axis of the hippocampus between anteroposterior (AP) levels -1.4 and $-3.4 \mathrm{~mm}$ from 
A

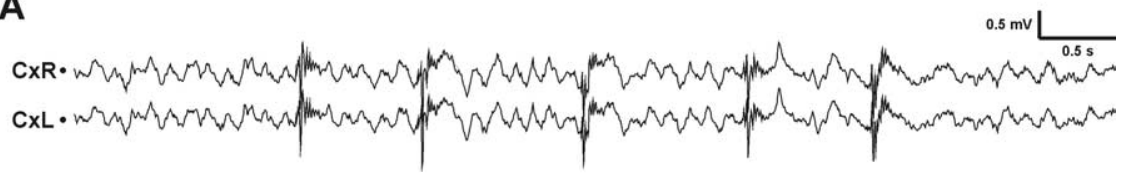

B
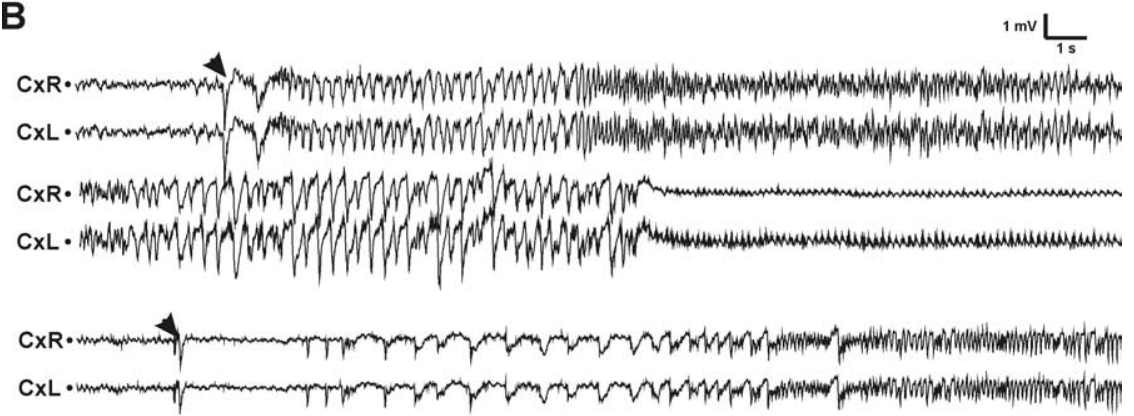

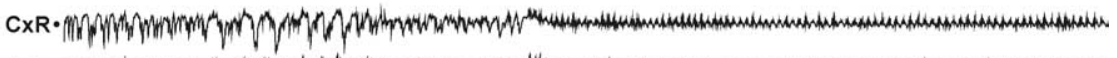

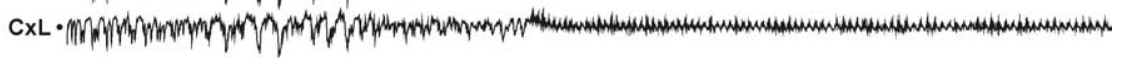

Figure 1. Epileptiform activity in APdE9 mice. $A$, Example of interictal spiking in an APdE9 mouse (18). Time bar, $0.5 \mathrm{~s}$; voltage bar, $0.5 \mathrm{mV}$. B, Examples of two spontaneous seizures in APdE9 mice. The first one (mouse 021) lasted for $35 \mathrm{~s}$ and was scored as 2 in the Racine scale based on behavioral observations, whereas the second one (mouse 251) lasted for $30 \mathrm{~s}$ and was scored as 3. The two EEG skull electrodes were located on the right (CXR) and left (CXL) frontal cortex. Both seizures began with a large-amplitude spike (arrowheads). The seizure in mouse 021 took place during waking immobility, whereas that in mouse 251 occurred during REM sleep. Both seizures were followed by regular low-amplitude oscillation of $\sim 7 \mathrm{~Hz}$. Time bar, $1 \mathrm{~s}$; voltage bar, $1 \mathrm{mV}$.

bregma (Hof et al., 2000). The density of mossy fiber sprouting was scored according to Cavazos et al. (1991): score 0, no granules; score 1, sparse granules in the supragranular region and in the inner molecular layer; score 2, granules evenly distributed throughout the supragranular region and the inner molecular layer; score 3 , almost a continuous band of granules in the supragranular region and inner molecular layer; score 4 , continuous band of granules in the supragranular region and in the inner molecular layer; score 5, confluent and dense laminar band of granules that covers most of the inner molecular layer, in addition to the supragranular region.

Amyloid plaque load was determined in anti-A $\beta$-stained sections, with four samples (two sections, both hemispheres) analyzed for each brain region. The regions and AP planes (relative to bregma) of the sections were as follows: dorsolateral cortex (motor area, AP, +0.9; perirhinal, AP, -2.4) and entorhinal cortex (AP, -3.3 and -3.6), hippocampus (AP, -2.1 and -2.4 ), amygdala (AP, -1.3 and -1.6 ), and thalamus (AP, -1.3 and -1.6$)$. In the final analysis, all four cortical samples were pooled, as were the two samples of other brain areas. Quantification of plaque load was done by calculating the plaque surface area as the percentage of total area analyzed using ImagePro Plus software (Media Cybernetics). Calbindin-D28k and NPY immunoreactivities were analyzed in five hippocampal sections stained along the septotemporal axis (AP between -1.6 and -2.7). Photomicrographs were taken on a Leica DM RB light microscope equipped with a Nikon DMX 1200F camera.

\section{Preparation of $A \beta 1-42$ and $A \beta 25-35$ species}

A $\beta 1-42$ was synthesized as described previously (Zarándi et al., 2007) by a solid-phase procedure involving Wang-resin and Fmoc chemistry. Crude peptide was purified on a C-4 RP-HPLC column; pure fractions were pooled and lyophilized. Purity control was achieved by amino acid analysis (HP Amino Quant amino acid analyzer) and mass spectrometry (ESI MS, FinniganMat TSQ 7000). Fibrillar $A \beta 1-42$ was prepared by incubating a $100 \mu \mathrm{M}$ peptide solution in MilliQ water at ambient temperature for $2 \mathrm{~d}$, followed by lyophilization. Before use, the solid, fibrillar peptide was suspended in artificial ACSF (ACSF), sonicated for $1 \mathrm{~min}$, and applied within $60 \mathrm{~min}$ at a final concentration of $1.0 \mu \mathrm{M}$. The fibrillar nature of $\mathrm{A} \beta 1-42$ has been confirmed by transmission electron microscopy and circular dichroism spectroscopy (Szegedi et al., 2006). Nonfi- brillar $\mathrm{A} \beta 1-42$ was obtained by dissolving the fibrillar peptide first in DMSO $(1 \mathrm{mg} / \mathrm{ml})$ and then diluting it into ACSF at a final concentration of $1 \mu \mathrm{M}$ as above.

A $\beta 25-35$ was synthesized as described previously (Harkany et al., 1998). A solution containing fibrillar A $\beta 25-35$ was conventionally prepared by suspending $A \beta 25-35$ in distilled water ( $0.5 \mathrm{~mm}$ in stock), followed by ultrasonication for $5 \mathrm{~min}$, and $1000 \times$ dilution to reach a final concentration of $2 \mu \mathrm{M}$. Nonfibrillar A $\beta 25-35$ oligomers were prepared by dissolution of A $\beta 25-35$ in DMSO ( $0.5 \mathrm{~mm}$ in stock), ultrasonication for $5 \mathrm{~min}$, and a subsequent $1000 \times$ dilution in extracellular solution to reach the desired final concentration of $2 \mu \mathrm{M}$. The presence of $A \beta 25-35$ fibrils formed freshly, and after incubation for $60 \mathrm{~min}$ at $37^{\circ} \mathrm{C}$ was studied by transmission electron microscopy as described previously (Shemer et al., 2006).

\section{Whole-cell patch-clamp recordings} Parasagittal cortical slices $(300 \mu \mathrm{m})$ were prepared from male APdE9 and wild-type littermates at the age of 3.5 months as described previously (Shemer et al., 2006). L2/3 pyramidal cells were selected using infrared differential interference (IR-DIC) contrast microscopy and subsequent characterization of their firing patterns. Somatic recordings were performed in whole-cell configuration, whereas extracellular afferent stimulation was induced via either a bipolar metal extracellular electrode (diameter, $50 \mu \mathrm{m}$; rate, $0.0133 \mathrm{~Hz}$ ) positioned in $\mathrm{L} 1$ or a glass pipette electrode at the L1/L2 border (see Fig. 5E). For bipolar metal electrodes, each stimulus consisted of a single pulse of $0.2 \mathrm{~ms}$. The extracellular solution contained (in mM) $125 \mathrm{NaCl}, 2.5 \mathrm{KCl}, 2 \mathrm{CaCl}_{2}, 1 \mathrm{MgCl}_{2}$, $25 \mathrm{NaHCO}_{3}, 1.25 \mathrm{NaH}_{2} \mathrm{PO}_{4}, 0.4$ ascorbic acid, and 25 glucose. Picrotoxin (100 $\mu \mathrm{M}$; Tocris) was applied extracellularly to block GABAergic neurotransmission as described previously (Wang et al., 2007). During current-clamp recordings while extracellular afferent stimulation was induced, patch pipettes were filled with (in $\mathrm{mm}$ ) $146 \mathrm{~K}$-gluconate, $9 \mathrm{KCl}$ 4 ATP-Mg, 10 Na-phosphocreatine, 0.3 GTP, and 10 HEPES (whole-cell recordings), or with $115 \mathrm{~K}$-gluconate, $20 \mathrm{KCl}, 4$ ATP_Mg, 10 Naphosphocreatine, 0.3 GTP_Na, and 10 HEPES (pH 7.3 adjusted by $\mathrm{NaOH}$ cell-attached recordings). Voltage-clamp recordings were performed with $20 \mathrm{~mm} \mathrm{KCl}$ in the intracellular solution. Recordings were made using the HEKA Elektronik EPC-10, Axopatch 200B, and Axoclamp 2B amplifiers (Molecular Devices). Input resistance $\left(R_{\mathrm{i}}\right)$ was monitored throughout the experiments by applying a $0.1 \mathrm{nA}$ hyperpolarizing pulse $(500 \mathrm{~ms})$ at the end of each sweep. More precisely, $R_{\mathrm{i}}$ was calculated from current-voltage $(I / V)$ relationships measured by applying incrementing current pulses $(500 \mathrm{~ms})$ at the range of resting potential. Continuous recordings were digitized $(10 \mathrm{kHz})$ on-line using Digidata 1322 (Molecular Devices) and analyzed off-line with Clampfit 9.0 (Molecular Devices). Otherwise, data were sampled at $100 \mu$ s intervals, digitized by an ITC-18 interface (InstruTECH) and stored for off-line analysis (Igor Pro; Wavemetrics). Patch pipettes were pulled from borosilicate glass (Harvard Apparatus ) and had a resistance of 3-5 $\mathrm{M} \Omega$. All experiments were performed at $32-34^{\circ} \mathrm{C}$ at a superfusion rate of $2-3 \mathrm{ml} / \mathrm{min}$. The threshold for action potential firing was determined either by somatic current injections or with presynaptic extracellular stimulation by increasing current strength until firing occurred. Input/output curves were constructed by normalizing the EPSP slope to the $50 \%$ of extracellular stimulus strength $(30 \mu \mathrm{A})$ (Knobloch et al., 2007). In experiments with acute application of $A \beta$ peptides, sagittal brain slices $(300 \mu \mathrm{m})$ were prepared from postnatal day 11 (P11) to P15 Swiss mice or Sprague Dawley rats of both sexes. Slices were then incubated in oligomeric/fibrillar A $\beta 25-35$ (rat) and $\mathrm{A} \beta 1-42$ (mouse) containing oxygenated $\mathrm{ACSF}$ at $20-22^{\circ} \mathrm{C}$ for $1 \mathrm{~h}$. Electrophysiology has been performed as above. $\mathrm{A} \beta 25-35$ was either 
dissolved in DMSO (1 mM stock) or applied to the superfusate (oligomeric $\mathrm{A} \beta$ ) or protofibrillar/aggregated $\mathrm{A} \beta 25-35$ was directly applied. To unequivocally define the membrane potential at which cells exposed to A $\beta 25-35$ or vehicle have generated action potentials, pyramidal cells were injected with a current ramp $(5-15 \mathrm{nA} / \mathrm{s}$ steps) via the somatic pipette. The extent of membrane depolarization required for induction of the first action potential $\left(\Delta V_{\text {ramp }}\right)$ was estimated from the formula $V_{\mathrm{RAMP}}-V_{\mathrm{R}}$.

\section{Extracellular recording of population activity}

Extracellular field potential recordings in L2/3 were performed in P15 wild-type male mice using electrodes made from borosilicate glass capillaries filled with ACSF. Nerves fibers were stimulated each $20 \mathrm{~s}$ via a bipolar metal extracellular electrode $(50 \mu \mathrm{m})$ positioned in L1. Each stimulus consisted of a single pulse of $0.2 \mathrm{~ms}$. Each slice was recorded before and after an acute bath application of fibrillar A $\beta 1-42(1 \mu \mathrm{M}, 1 \mathrm{~h})$ without modifying the position of either the field or the stimulation electrode, or the stimulus strength. Recordings were digitized $(50 \mathrm{kHz})$ and analyzed off-line using Igor Pro 5 (Wavemetrics). Each field potential was analyzed for $80 \mathrm{~ms}$ after stimulus application. The extracellular field response consists primarily of action potentials of a large population of $\mathrm{L} 2 / 3$ neurons in response to the pulse stimulation. The integrated activity parameter represents a scalar integral of the average of 10 events.

\section{Single-channel recordings}

Brain slices were prepared from male APdE9 mice and wild-type littermate controls aged 4-5 months or from P11-P15 wild-type mice. Animals were decapitated under Na-chloral anesthesia $(100 \mathrm{mg} / \mathrm{kg})$, and brains were rapidly removed. Sagittal slices $(300 \mu \mathrm{m})$ were cut using a Microm tissue slicer (International) with ice-cold oxygenated modified ACSF, with $0.5 \mathrm{~mm} \mathrm{CaCl}_{2}$ and $7 \mathrm{~mm} \mathrm{MgSO}_{4}$, and in which $\mathrm{Na}^{+}$was replaced by an equimolar concentration of choline. Slices were then transferred into oxygenated ACSF containing (in mM) $126 \mathrm{NaCl}, 3.5 \mathrm{KCl}$, $1.2 \mathrm{NaH}_{2} \mathrm{PO}_{4}, 26 \mathrm{NaHCO}_{3}, 1.3 \mathrm{MgCl}_{2}, 2.0 \mathrm{CaCl}_{2}$, and 10 D-glucose [pH 7.4 at room temperature $\left(20-22^{\circ} \mathrm{C}\right)$ for at least $1 \mathrm{~h}$ before use]. For recordings, slices were placed into a conventional fully submerged chamber superfused with ACSF $\left(32-34^{\circ} \mathrm{C}\right)$ at a rate of $2-3 \mathrm{ml} / \mathrm{min}$. Cell types were identified by IR-DIC video microscopy. Patch-clamp recordings were performed using dual EPC-10 amplifiers (HEKA Elektronik). Pipettes (resistance, of 3.5-8 M $\Omega$ ) were pulled from borosilicate glass capillaries. For recordings of single NMDA channels, the pipette solution contained (in mM) $140 \mathrm{NaCl}, 2.5 \mathrm{KCl}, 2 \mathrm{CaCl}_{2}, 10$ HEPES, $0.01 \mathrm{NMDA}$, and 0.01 glycine ( $\mathrm{pH}$ adjusted to 7.3 by $\mathrm{NaOH}$ ). Resting membrane potential $\left(V_{\mathrm{R}}\right)$ was estimated using cell-attached recordings of single NMDA channels as described previously (Tyzio et al., 2003). Analysis of currents through single channels and $I / V$ relationships were performed using Clampfit 9.2 (Molecular Devices).

\section{Statistical analysis}

Histological, video-EEG, and electrophysiology data were analyzed using the two-tailed Student's $t$ test (SPSS for Windows, version 11.5.1; SPSS). The extent of mossy fiber sprouting and amyloid burden in different brain regions was analyzed with Student's $t$ test. The presence of plaques in the thalamus was assessed with the nonparametric Mann-Whitney $U$ test. The distribution of calbindin and NPY alternations between groups was analyzed with the Kruskal-Wallis test. Data were expressed as means \pm SEM throughout. The level of significance was set at $p<0.05$.

\section{Results}

Video-EEG shows high incidence of seizures in APdE9 mice

During the first 2 weeks of video-EEG recording (age, 3-3.5 months), 5 of 20 APdE9 mice (25\%) had at least one electrographic seizure. None of the 10 wild-type littermates exhibited seizure activity. In the third week of recording (age, 4.5 months), the proportion of $A P d E 9$ mice with seizures increased to 11 of 20 (55\%). In total, 13 (65\%) APdE9 mice, but none of the wild-type controls, exhibited at least one electrographic seizure during a cumulated 3 week recording period (see Fig. $2 \mathrm{~A}$ ). In contrast, rare spontaneous spikes were observed in 2 of 10 wild-type mice.

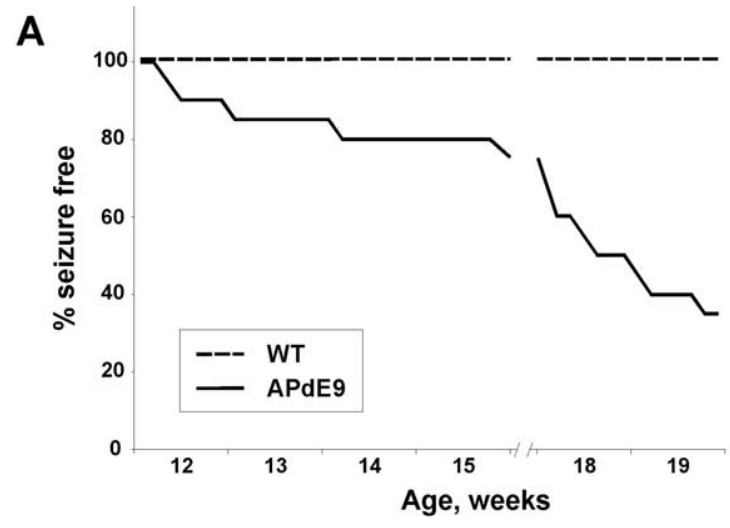

B

\begin{tabular}{|c|c|c|c|c|c|c|c|c|c|c|}
\hline \multirow{2}{*}{\multicolumn{2}{|c|}{$\begin{array}{c}\text { Mouse } \\
\text { ID }\end{array}$}} & \multirow{2}{*}{$\begin{array}{l}\text { Seizures } \\
\text { in total }\end{array}$} & \multicolumn{3}{|c|}{ Seizures per week } & \multirow{2}{*}{$\begin{array}{c}\text { Mean } \\
\text { dur. (s) }\end{array}$} & \multirow{2}{*}{\begin{tabular}{|c|} 
Mean \\
beh. \\
score
\end{tabular}} & \multirow{2}{*}{$\begin{array}{c}\text { Gen. } \\
\text { sz. (\%) }\end{array}$} & \multirow{2}{*}{ CB } & \multirow{2}{*}{ NPY } \\
\hline & & & Per 1 & Per 2 & Per 3 & & & & & \\
\hline 1 & 021 & 23 & 7 & 6 & 10 & 27 & 2.2 & 53 & - & + \\
\hline 2 & 251 & 8 & 7 & 0 & 1 & 26 & 1.9 & 50 & - & + \\
\hline 3 & 328 & 4 & 0 & 0 & 4 & 32 & 4.5 & 100 & $\mathrm{~N} / \mathrm{A}$ & N/A \\
\hline 4 & 036 & 4 & 0 & 0 & 4 & 21 & 0.5 & 0 & + & - \\
\hline 5 & 339 & 3 & 2 & 1 & 0 & 29 & 1.8 & 33 & + & - \\
\hline 6 & 035 & 3 & 0 & 0 & 3 & 37 & 0 & 0 & + & - \\
\hline 7 & 003 & 1 & 0 & 1 & 0 & 15 & 3 & 100 & N/A & N/A \\
\hline 8 & 018 & 1 & 0 & 1 & 0 & 19 & 1 & 0 & + & - \\
\hline 9 & 020 & 1 & 0 & 0 & 1 & 27 & 0 & 0 & N/A & N/A \\
\hline 10 & 324 & 1 & 0 & 0 & 1 & 14 & 2 & 0 & N/A & N/A \\
\hline 11 & 327 & 1 & 0 & 0 & 1 & 40 & 0 & 0 & N/A & N/A \\
\hline 12 & 335 & 1 & 0 & 0 & 1 & 54 & 2 & 0 & + & + \\
\hline 13 & 346 & 1 & 0 & 0 & 1 & 19 & 0 & 0 & N/A & N/A \\
\hline \multicolumn{2}{|c|}{ Average } & 4.0 & 1.2 & 0.7 & 2.1 & 28 & 1.5 & 26 & & \\
\hline 14 & 004 & 0 & 0 & 0 & 0 & 0 & 0 & 0 & + & - \\
\hline 15 & 006 & 0 & 0 & 0 & 0 & 0 & 0 & 0 & + & - \\
\hline 16 & 033 & 0 & 0 & 0 & 0 & 0 & 0 & 0 & + & - \\
\hline 17 & 200 & 0 & 0 & 0 & 0 & 0 & 0 & 0 & + & - \\
\hline 18 & 338 & 0 & 0 & 0 & 0 & 0 & 0 & 0 & + & - \\
\hline 19 & 353 & 0 & 0 & 0 & 0 & 0 & 0 & 0 & + & - \\
\hline 20 & 396 & 0 & 0 & 0 & 0 & 0 & 0 & 0 & + & + \\
\hline
\end{tabular}

Figure 2. Prevalence and characteristics of seizures in $A P d E 9$ mice. $A$, The cumulative proportion (percentage) of $A P d E 9$ mice $(n=20$ ) remaining seizure free during the video-EEG monitoring as a function of their true biological age. The gap between 15 and 18 weeks of age indicates the interval between the first ( 2 weeks) and the second (1 week) recording periods. WT, Wild type. $\boldsymbol{B}$, Prevalence and characteristics of seizures in APdE9 mice $(n=20)$. In this table, the video-EEG recording has been divided into three periods (Per) of 1 week each. Mean dur., Mean seizure duration; Mean beh. score, mean behavioral score in Racine's scale; Gen. sz. (\%), percentage of generalized seizures of all seizures. The two rightmost columns represent alterations in hippocampal calbindin (CB) and NPY staining. For CB staining, + means presence of normal immunoreactivity; for NPY staining, + means presence of ectopic immunoreactivity in mossy fibers. N/A, Data not available [we chose 7 APdE9 mice with at least one unprovoked seizure and 7 APdE9 mice with no detectable seizures for immunostaining together with 7 wild-type mice (not included in the table)].

However, epileptiform spikes were present in 13 of 20 APdE9 mice ( 3 of 7 without seizures and 10 of 13 with seizures). Figure $1 A$ illustrates typical interictal activity of an APdE9 mouse, and Figure $1 B$ demonstrates two typical seizures, which begin with a large-amplitude spike and are followed by a period of regular low-amplitude oscillation in the theta range $(7 \mathrm{~Hz})$. In all cases observed, seizure onset was precisely identical in both cortical channels. Up to $42 \%$ of the seizures were secondarily generalized. The number of seizures per animal varied greatly: most mice had only one seizure during the follow-up period, whereas one mouse (021) had as many as 23 seizures (Fig. $2 B$ ). The mean seizure frequency was $0.18 \pm 0.07$ seizures/d (median, 0.06 ; range, $0.05-$ 

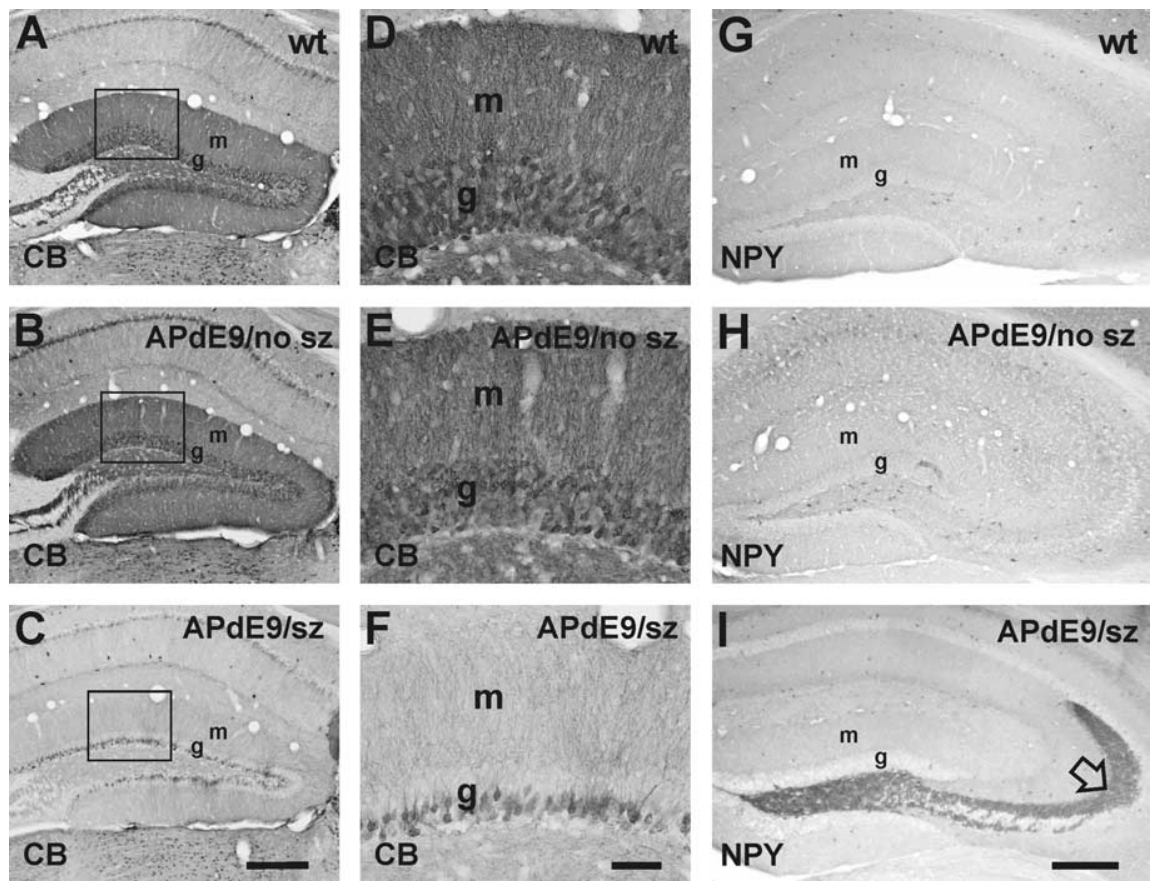

Figure 3. Calbindin-D28k and NPY in the dentate gyrus of $A P d E 9$ mice. $\boldsymbol{A}, \boldsymbol{D}$, Wild-type mouse. $\boldsymbol{B}, \boldsymbol{E}, A P d E 9$ mouse with no seizures. $\boldsymbol{C}, \boldsymbol{F}, A P d E 9$ mouse (021) with multiple seizures. $\boldsymbol{D}-\boldsymbol{F}$ are zoomed in from the rectangle shown in $\boldsymbol{A}-\boldsymbol{C}$. Note a dramatic decrease in calbindin $(C B)$ staining in the dentate $G C S$ of the $A P d E 9$ mouse with seizures. This corresponded with the decrease in calbindin immunoreactivity in the molecular layer. NPY immunostaining of the septal hippocampus revealed overexpression in mossy fibers in some APdE9 but in none of the wild-type animals (I; open arrow). $\boldsymbol{G}$, Wild-type mouse. $\boldsymbol{H}, A P d E 9$ mouse with no seizures (no sz). I, APdE9 mouse (251) with multiple seizures (sz). wt, Wild type; $g$, GC layer; $m$, molecular layer. Scale bars: $\boldsymbol{A}-\boldsymbol{C}$, G-I, $250 \mu \mathrm{m} ; \boldsymbol{D}-\boldsymbol{F}, 50 \mu \mathrm{m}$.

0.96). The mean duration of seizures was $28 \pm 14 \mathrm{~s}$ (median, $23 \mathrm{~s}$; range, 5-63 s). A substantial proportion of mice with seizures $(38 \%)$ had at least one generalized seizure. One subject (328) eventually died because of a prolonged status epilepticus during video-EEG recording. Albeit an individual case in a size-limited cohort of study objects, this incident clearly indicates that seizures in APdE9 mice may be fatal.

\section{High seizure frequency associates with neuromorphological changes in APdE9 mice}

At the end of the recording period, we assessed the most frequent morphological changes described in the rodent hippocampus in association with electrically or chemically induced seizures: sprouting of dentate GC axons (mossy fibers) intruding into the supragranular region and inner molecular layer of the dentate gyrus (Tauck and Nadler, 1985), loss of calbindin-D28k immunoreactivity in GCs (Tonder et al., 1994), and ectopic NPY expression in mossy fibers (Vezzani et al. 1999). Of these, both calbindin-D28k (Palop et al., 2007) and NPY (Diez et al., 2003; Palop et al., 2007) alterations have been reported also in APP transgenic mice. In addition, we compared the regional distribution and surface area (A $\beta$ burden) with the frequency of epileptic seizures. Mossy fiber sprouting was assessed in Timm-stained sections of the hippocampus using the conventional scoring from 0 to 5 (Cavazos et al., 1991). Overall, there was little sprouting, and the average score of all mice fell below 1 (wild type, $0.16 \pm$ 0.02; APdE9 without seizures, $0.18 \pm 0.04$; $A P d E 9$ with seizures, $0.28 \pm 0.07)$. Although there was a trend toward higher scores in APdE9 mice with seizures, the overall difference did not reach significance $\left(F_{(2,23)}=1.2 ; p=0.31\right)$. Calbindin-D28k depletion was present in the dentate gyrus only in two of seven APdE9 animals (021 and 251) with seizures and was absent in all examined wild-type $(n=$ 7) mice and $A P d E 9$ mice without seizures $\left(n=7 ; \chi^{2}=4.2 ; p=0.12\right)$. Notably, in both cases the calbindin-D28k depletion was robust (Fig. $3 A-F$ ), and these were the mice exhibiting the highest frequency of seizures, half of which were generalized (Fig. 2B). Strong NPY immunoreactivity in mossy fibers extending to the CA3 was present in three APdE9 animals $(n=7)$ with seizures $(021,251,335)$ and in one APdE9 animal $(n=7)$ without seizures (396). In contrast, none of the control mice $(n=7)$ displayed an aberrant NPY immunolabeling pattern $\left(\chi^{2}=4.1 ; p=\right.$ 0.12 ) (Figs. 2C, 3G-I).

$\mathrm{A} \beta$ burden (total plaque area per total section area) was determined using a human-specific anti-A $\beta$ antibody in the neocortex, hippocampus, amygdala, and thalamus. As shown in Figure 4, regional differences in $\mathrm{A} \beta$ burden were consistent with previous findings in APPoverexpressing mice: the highest amyloid plaque load was found in neocortical areas, followed by the amygdala and hippocampus. Plaques were encountered in the thalamus only in three APdE9 mice without seizures $(n=7)$, whereas all APdE9 mice with seizures $(n=13)$ were plaque free $(U=26 ; p=0.01)$. In other brain regions, $A P d E 9$ with and without seizures did not differ in the extent of $\mathrm{A} \beta$ burden ( $p>0.12$ in all comparisons). If anything, mice with seizures displayed lower $\mathrm{A} \beta$ burden in all brain areas.

\section{Hyperexcitability of cortical pyramidal cells in APdE9 mice}

As a possible mechanism of the increase in seizure susceptibility, we suggested that age-dependent $\mathrm{A} \beta$ accumulation could result in a gradual and sustained membrane depolarization. This would facilitate seizure development by (1) a decrease in postsynaptic potential size necessary to activate pyramidal cells and (2) a partial relief of NMDA channels from their $\mathrm{Mg}^{2+}$ block. We have measured $V_{\mathrm{R}}$ noninvasively in L2/3 pyramidal neurons in APdE9 transgenic mice (age, 4-5 months) and in age-matched wild-type littermates (Fig. 5A): $V_{\mathrm{R}}$ was significantly depolarized in APdE9 mice (wild-type mice, $-79.95 \pm 1.41 \mathrm{mV}, n=13$; APdE9 mice, $-68.41 \pm 2.20 \mathrm{mV}, n=14 ; p=0.001)$. Sustained $V_{\mathrm{R}}$ depolarization of L2/3 pyramidal cells in APdE9 mice was confirmed by whole-cell recordings showing that increased somatic current injection evokes action potential firing (wild type, $n=6$; APdE9, $n=9$ ) (Fig. $5 B$ ) with higher probability and at remarkably lower current thresholds than in age-matched wild-type littermates (Fig. 5D). Nevertheless, L2/3 pyramidal cells from transgenic and wild-type mice reached identical maximal ex vivo firing frequencies (Fig. 5C). $R_{\mathrm{i}}$ remained unchanged throughout (control, $86.5 \pm 16.4 \mathrm{M} \Omega$ vs $A P d E 9,96.6 \pm 11.6 \mathrm{M} \Omega$ ). We also confirmed the above findings by using extracellular stimulation of L1 afferents in wild-type $(n=4)$ and $\operatorname{APdE9}(n=8)$ mice. Particular care was taken to assure essentially identical electrode placement along the apical dendritic tuft of L2/3 pyramids (Fig. 5E). Afferent stimulation strengths that invariably evoked EPSPs in wild-type neurons commonly evoked APs in APdE9 neurons instead at 

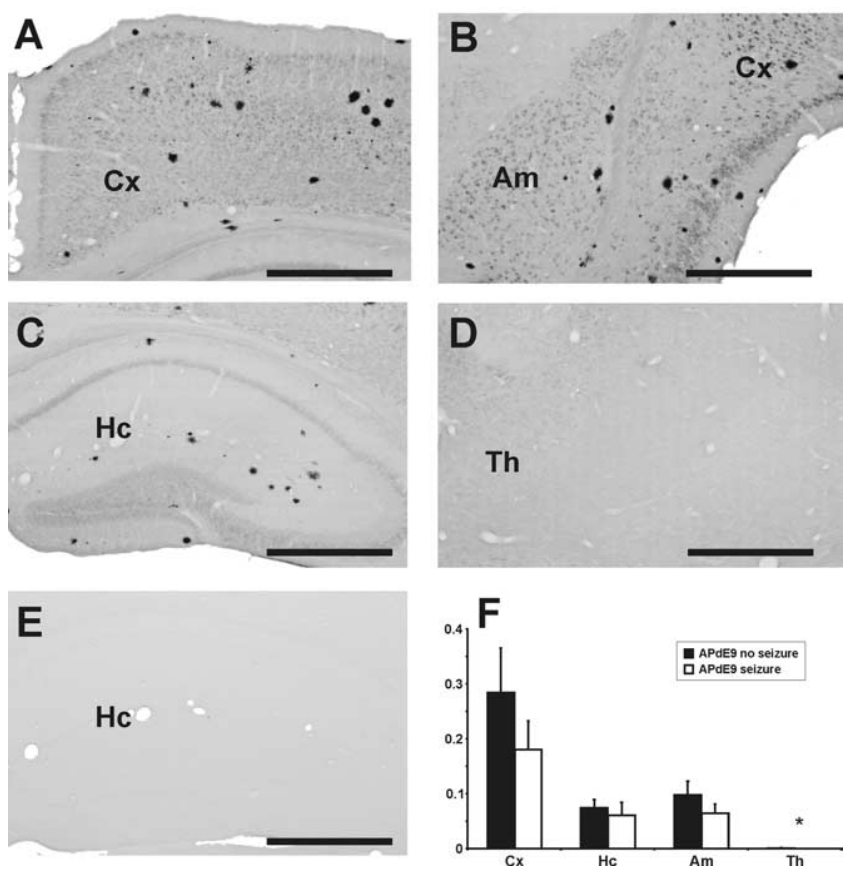

Figure 4. Plaque distribution in telencephalic areas of $A P d E 9$ mice. Anti-human $A \beta$ staining (W0-2) in APdE9 mice at the end of the study (age, 5 months) revealed a substantial number of amyloid plaques in the cortex, hippocampus, and amygdala, but hardly any plaques in the thalamus. $\boldsymbol{A}-\boldsymbol{D}$, The coronal sections of an APdE9 mouse are at the levels of motor cortex $(\boldsymbol{A})$, amygdala and perirhinal cortex $(\boldsymbol{B})$, septal hippocampus $(\boldsymbol{C})$, and dorsal thalamus just below the septal hippocampus (D).E, A corresponding hippocampal section of a wild-type mouse showing even no intracellular staining for human $A \beta$. Scale bars, $500 \mu \mathrm{m}$. F, Amyloid burden expressed as immunoreactive surface area in the percentage of the total area of analyzed sections. Student's $t$ test did not reveal significant differences in plaque load between APdE9 mice with or without seizures for motor, perirhinal, and entorhinal cortices ( $p=0.34$ ), hippocampus ( $p=$ $0.34)$, and amygdala ( $p=0.08)$. ${ }^{*}$ In the thalamus, more APdE9 mice without seizures had plaques than mice with seizures ( $p=0.01$, Mann-Whitney $U$ test). $C x$, Perirhinal and entorhinal cortices; Hc, hippocampus; Am, amygdale; Th, thalamus.

stimulus strengths exceeding $20 \mu \mathrm{A}$ ( $p<0.05$ in the range of 35-45 $\mu$ A stimulus strength) (Fig. 5F, G). Because the distance of stimulus points from the soma of L2/3 pyramidal cells did not differ considerably in our assays, and the population size in independent experiments (number of cells from many transgenics and wild-type mice) was relatively large, we argue that the difference in pyramidal cell excitability observed in this paradigm is a true reflection of phenotypic changes imposed by transgene overexpression in APdE9 mice.

To unequivocally demonstrate whether neuronal hyperexcitability was related to the presence of a particular form of bathapplied $\mathrm{A} \beta$ (Fig. $6 \mathrm{~A}$ ), we noninvasively measured $V_{\mathrm{R}}$ in $\mathrm{L} 2 / 3$ pyramidal neurons by measuring the NMDA-induced current reversal potential in cell-attached recordings in wild-type juvenile mice (age, P14-P15) in control medium and after acute bath application of fibrillar A $\beta 1-42(1 \mu \mathrm{M})$ (Fig. $6 B)$. $V_{\mathrm{R}}$ was significantly depolarized after application of $\mathrm{A} \beta 1-42$ (control, $-81.99 \pm 1.35 \mathrm{mV}, n=18$; after application of $\mathrm{A} \beta 1-42$, $-68.36 \pm 1.71 \mathrm{mV}, n=13 ; p<0.001$ ) (Fig. 6C). $R_{\mathrm{i}}$ remained unchanged throughout (control, $188.3 \pm 18 \mathrm{M} \Omega$ vs $\mathrm{A} \beta 1-42$, $208.9 \pm 22.6 \mathrm{M} \Omega$ ). Because hippocampal neuronal networks have directly been implicated in the process of seizure generation in a transgenic mouse model of AD (Palop et al., 2007), we have expanded the above findings and show that $\mathrm{A} \beta$-induced hyperexcitability is a widespread phenomenon also affecting dentate GCs (Fig. 6C). $V_{\mathrm{R}}$ of GCs was significantly depolarized after ap- plication of $\mathrm{A} \beta 1-42$ (control, $-91.16 \pm 2.23 \mathrm{mV}, n=12$; after application of $\mathrm{A} \beta 1-42,-76.53 \pm 2.39 \mathrm{mV}, n=14 ; p<0.001)$. To address whether fibrillar $\mathrm{A} \beta$ is essential to elicit rapid excitability changes, we also compared the effects of (proto-)fibrillar $\mathrm{A} \beta 1-42$ with that of oligomeric $\mathrm{A} \beta 1-42$ (Fig. $6 A$ ). As Figure $6 B$ shows, $V_{\mathrm{R}}$ depolarization was exclusively found after application of (proto-)fibrillar A $\beta 1-42$ to L2/3 pyramidal cells in cellattached recordings. These findings were confirmed by comparing the effects of (proto-)fibrillar versus oligomeric A $\beta 25-35$ (Fig. 6A) in whole-cell patch-clamp recordings on $\mathrm{L} 2 / 3$ neocortical pyramids (Fig. 6D) (Shemer et al., 2006). As shown in Figure $6, D$ and $D^{\prime}$, application of depolarizing current ramps triggered action potential firing from deeper membrane potentials after exposure to fibrillar A $\beta 25-35$ compared with vehicle. Oligomeric forms of this $\mathrm{A} \beta$ species remained ineffective on $V_{\mathrm{R}}$. Thus, $\Delta V$ required for action potential generation was significantly decreased by fibrillar A $\beta 25-35(p<0.05)$ (Fig. 6D).

To reinforce that a $10-15 \mathrm{mV}$ membrane depolarization results in a significant change in pyramidal cell excitability, we performed whole-cell current-clamp recordings in an APdE9 $\mathrm{L} 2 / 3$ pyramidal cell held at $-80 \mathrm{mV}$ (corresponding to the mean $V_{\mathrm{R}}$ in wild types) while stimulating $\mathrm{L} 1$ afferents (Fig. $5 E$ ). Single pulses $(0.2 \mathrm{~ms})$ induced polysynaptic subthreshold EPSPs in the pyramidal cell (Fig. 6E). However, when the pyramidal cell was depolarized by $\sim 10 \mathrm{mV}$, similar extracellular stimulation evoked reliable action potential firing (Fig. $6 E$ ). Overall, age-dependent $\mathrm{A} \beta$ accumulation results in massive membrane depolarization that enhances the excitability of pyramidal cells and therefore may play a principal role in the process of seizure development.

One may assume that $V_{\mathrm{R}}$ changes also affect other than pyramidal cells in the neocortex and thus could compensate for changes in an enhanced excitatory tone in cortical neuronal networks. We addressed $\mathrm{A} \beta 1-42$-induced changes in excitation/inhibition balance by recording extracellular field potentials in $\mathrm{L} 2 / 3$ pyramidal cells while stimulating afferent fibers in L1 before and after acute bath application of fibrillar $A \beta 1-42$. As a quantitative measure, we used an integrated activity parameter representing a scalar integral of the average of 10 events. As shown in Figure 6, $F$ and $F^{\prime}$, bath application of fibrillar $\mathrm{A} \beta 1-42$ resulted in a significant increase in the neuronal population activity $\left[(2.4 \pm 0.8) * 10^{-3}\right.$ $\mathrm{mV}^{\star} \mathrm{ms}$ in control slices and $(4.3 \pm 0.8)^{*} 10^{-3} \mathrm{mV}^{\star} \mathrm{ms}$ after bath application of A $\beta 1-42 ; n=4$ (two animals); $p<0.02$, Student's $t$ test]; $\Omega$ indicates a shift in network activity toward excitation.

\section{Discussion}

The present study is a pioneering attempt to systematically determine the prevalence of seizures in a mouse model of AD. We found a high probability of epileptic seizures in young APdE9 mice at the age when the first amyloid plaques appear, but no evidence of seizures in wild-type littermates. Moreover, onefourth of the APdE9 mice exhibited generalized seizures, and one mouse died of spontaneous prolonged status epilepticus during the study. These data suggest that prolonged seizures may account for the early premature death in APP transgenic mouse lines. Morphological alterations characteristic of induced seizures such as ectopic NPY expression in mossy fibers were observed in only a subset of animals, but interestingly, in those with the most severe epilepsy phenotype. In addition, electrophysiological recordings in brain slices revealed increased excitability and abnormal depolarization of $V_{\mathrm{R}}$ in cortical pyramidal cells of $A P d E 9$ mice compared with wild-type littermates. Similar depolarization of resting membrane potential was observed in both cortical and hippocampal slices of wild-type mice when they were 

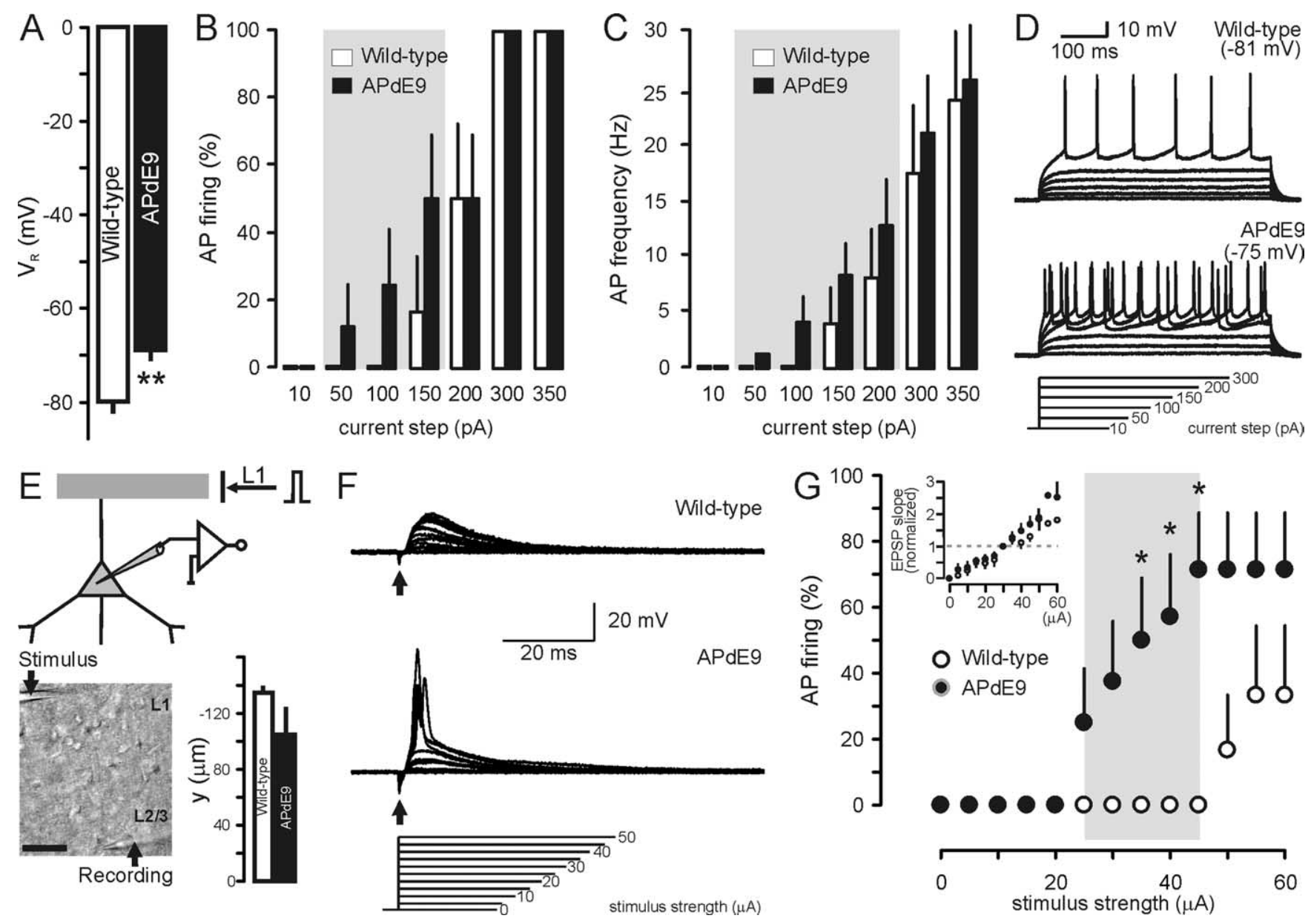

Figure 5. Increased neuronal excitability in $A P d E 9$ mice. $\boldsymbol{A}$, Resting membrane potential $\left(V_{R}\right)$ of $L 2 / 3$ pyramidal cells in $A P d E 9$ and wild-type mice at the age of 6 months. $\boldsymbol{B}, \boldsymbol{C}$, Incrementing current injection in the soma of $L 2 / 3$ pyramids leads to premature action potential (AP) firing in APdE9 mice at subthreshold current steps compared with neurons from wild-type mice as early as 3.5 months of age. $\boldsymbol{D}$, Representative recording traces. $\boldsymbol{E}$, Schematic illustration of the $\mathrm{L} 1$ afferent stimulation paradigm. The inset shows a representative experimental setting. The bar graph indicates the relative distance of stimulating pipettes along the apical tuft of pyramidal cells from their somata. $\boldsymbol{F}$, Representative recordings with incrementing extracellular stimulus strengths at 3.5 months of age. G, Cumulative analysis of neuronal excitability in response to afferent stimulation in APdE9 $(n=8)$ and wild-type $(n=6)$ slices. ${ }^{*} p<0.05$, ${ }^{* *} p<0.01$ versus wild type.

preincubated with fibrillar $\mathrm{A} \beta 1-42$ peptide, the most prevalent A $\beta$ species in the APdE9 mouse model (Jankowsky et al., 2004). Collectively, these findings suggest that accumulation of $\mathrm{A} \beta$ makes principal neurons hyperexcitable and renders neural networks susceptible for epileptiform activity.

\section{Epileptic seizure may underlie premature death in APP transgenic mice}

Premature death of unknown origin of mice overexpressing human wild-type or mutated $A P P$ was a common problem of early AD mouse models (Carlson et al., 1997) but has recently been primarily ignored. With the exception of isolated reports of convulsive seizures (Hsiao et al., 1995), epilepsy has not been linked with the expression of the APP transgene in mice until a recent report (Palop et al., 2007) describing nonconvulsive seizures in a small number of APP transgenic mice. Although those mice carrying human $A P P$ with Swedish and Indiana mutations display a similar $10 \%$ prevalence of premature deaths as our APdE9 mouse (Chin et al., 2004), no convulsive seizures were detected in that study, whereas $38 \%$ of our mice with seizures displayed at least one generalized seizure. Thus, it remains open whether prolonged seizures are a major cause of premature deaths in APP transgenic mice in general.

The electrographic characteristics of seizures described by
Palop et al. (2007) do not differ from those observed in our study. Seizure-associated neuropathological findings were also surprisingly similar between these two animal models: neither study found evidence of mossy fiber sprouting into the inner molecular layer, a common finding in experimental and human temporal lobe epilepsy, whereas in both studies the mice with the highest number of seizures displayed the most severe loss of calbindinD28k immunoreactivity in dentate GCs and abnormal NPY immunoreactivity in mossy fibers projecting to the CA3. One notable difference is the higher presence of the above-mentioned changes as well as increased NPY immunoreactivity in the two outer thirds of the dentate molecular layer in the study by Palop et al. (2007). The authors interpreted these changes as compensatory network changes that counteract initial overexcitability and protect from generalized seizures (Palop et al., 2007), thus leaving the cause of seizures in APP transgenic mice still open.

\section{Cumulative evidence establishes $A \boldsymbol{\beta}$ as a cause of epilepsy in} APP mice

$A P d E 9$ mice carry familiar AD-related APP and PS1 gene mutations, which both promote accumulation of $A \beta 1-42$ peptide in the brain and deposition into amyloid plaques. Which pathological aspect then renders the mice susceptible for epileptic seizures? Accumulating evidence ascribes a key role of elevated $\mathrm{A} \beta$ 
levels in this process. The seizure prevalence in APdE9 mice increased between 3 and 4.5 months of age, speaking for an ongoing process rather than an abnormality present already at birth. Notably, this is the age range when the first amyloid plaques develop in the cortex and hippocampus of these mice (Shemer et al., 2006). Indeed, a recent calcium imaging study reported hyperactive neurons to cluster around amyloid plaques in the cortex of $A P P / P S 1$ mice (Busche et al., 2008), which points to a key role of amyloid liberation and progressive extracellular accumulation in seizure initiation. However, amyloid plaques per se are an unlikely cause for seizures. First, $A P d E 9$ mice with seizures in our study had no more plaques than $A P d E 9$ mice without seizures. Second, earlier literature describes premature deaths in APP transgenic before any amyloid plaques could be detected (Hsiao et al., 1995; Carlson et al., 1997). Third, in the recent study by Palop et al. (2007), elevation of NPY immunoreactivity in the dentate gyrus was similar in three independent mouse lines carrying familiar AD-associated APP mutations but varying vastly in their amyloid plaque loads. Nevertheless, our finding that increased neuronal excitability in brain slices of APdE9 mice can be mimicked by preincubation of wild-type slices with fibrillar but still soluble $\mathrm{A} \beta$ peptides strongly supports the concept that $A \beta$ is the primary trigger for the overexcitability. We hypothesize that disruption of neuronal membrane integrity by insertion of (proto-)fibrillar $\mathrm{A} \beta$ before plaque formation yields robust changes to $V_{\mathrm{R}}$. Subsequent disruption of, for instance, voltagedependent channel functions (Talley et al., 2003; Ye et al., 2003; Misonou et al., 2005; Plant et al., 2006; Lima et al., 2008) pertinent to maintain a stable, hyperpolarized plasmalemmal membrane potential may underscore sustained membrane depolarization. This notion is also consistent with the observations of lowered seizure thresholds after systemic challenge with pentylentetrazol not only in plaque-bearing $A P P$ transgenic mice (Palop et al., 2007) but also in those with elevated levels of soluble $\mathrm{A} \beta$ aggregates but no plaques (Del Vecchio et al., 2004; Palop et al., 2007). Intriguingly, all reported mouse lines showing epilepsy-associated morphological changes and lowered seizure thresholds had APP mutations favoring the formation of the more easily aggregating A $\beta 1-42$ form (Palop et al., 2007). Similarly, the combination of PS1dE9 with APPswe mutation strongly shifts the gamma-cleavage of $A \beta$ toward $A \beta 1-42$ (Jankowsky et al., 2004; Minkeviciene et al., 2008). However, because it is well established that $A P P$-induced lethality is highly

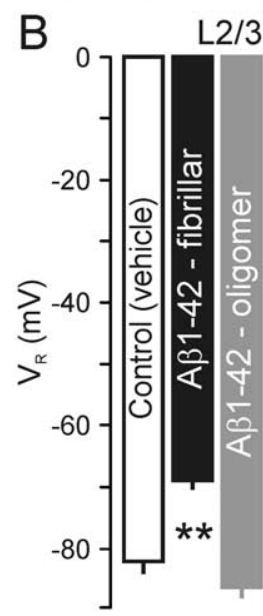

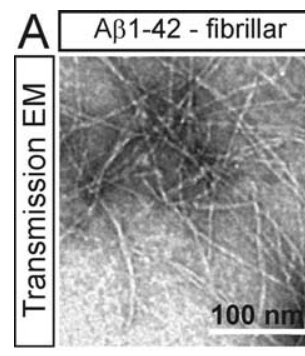
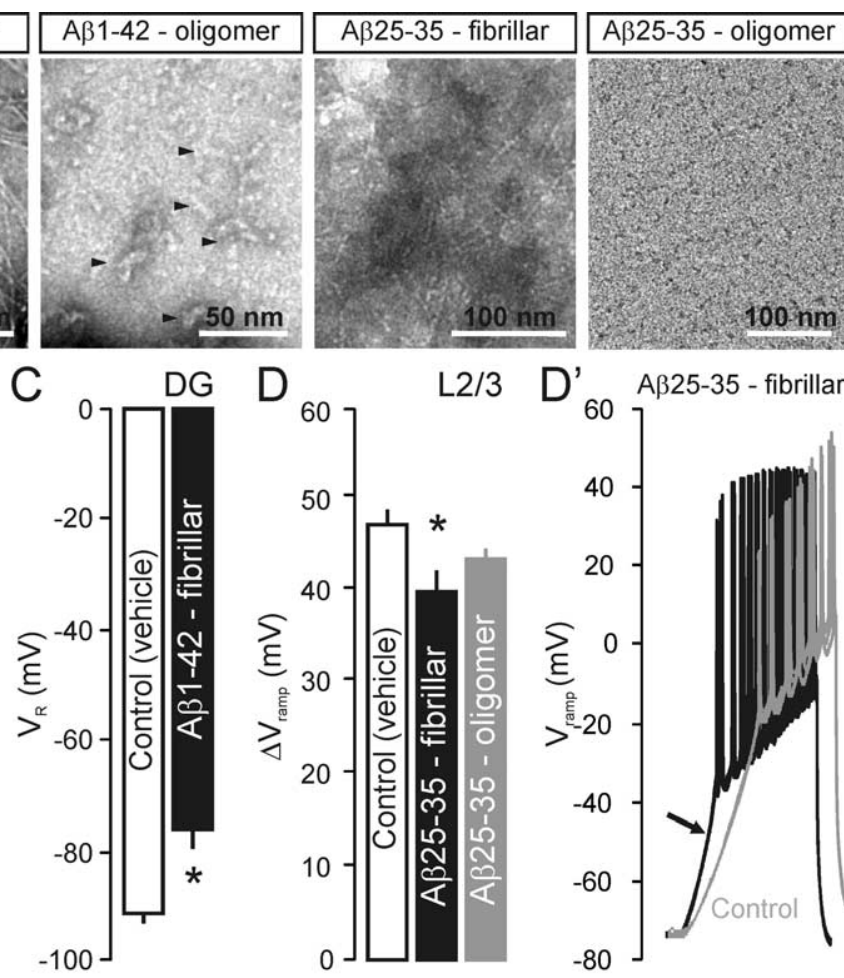

$D_{60}$ A $325-35$ - fibrillar
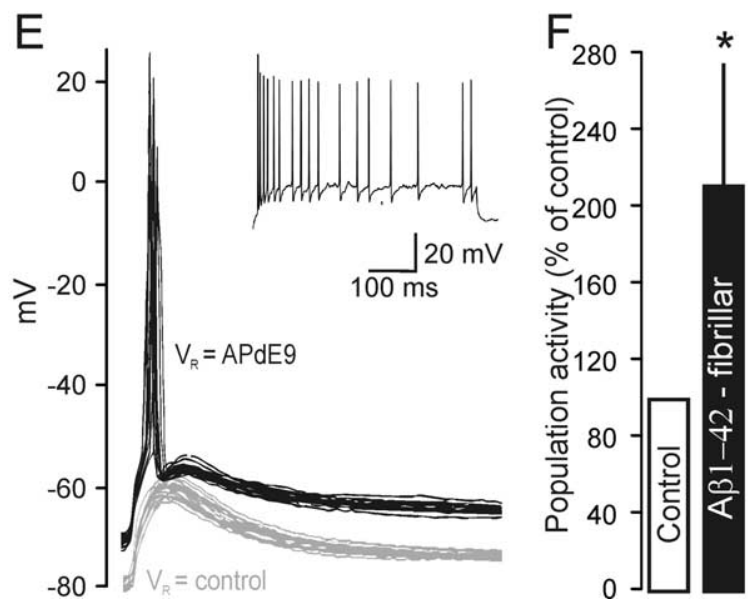

$-80$

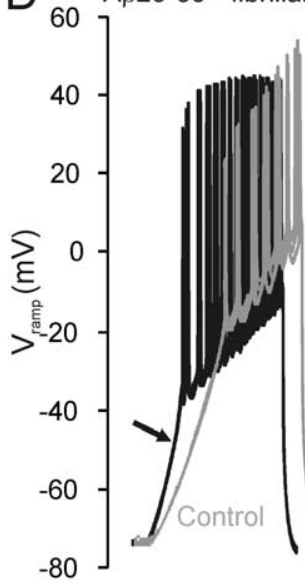

Figure 6. Fibrillar $A \beta$ affects neuronal excitability. $A$, Transmission electron microscopy (EM) images of $A \beta 1-42$ and A $\beta 25-35$ fibrils dissolved in water (fibrillar) or in DMSO, a chaotic solvent. Note that DMSO pretreatment eliminated preformed $A \beta$ (proto-)fibrils in both cases and generated small oligomers for $A \beta 1-42$ (arrowheads) instead. DMSO-pretreated A $\beta 25-35$ could not be observed by transmission electron microscopy because of the relatively low resolution of the applied protein staining technique, which made the $A \beta 25-35$ monomers/low-molecular-weight oligomers indetectable (Shemer et al., 2006). B, C, Fibrillar but not oligomeric $A \beta 1-42$ depolarizes both $L 2 / 3$ pyramidal cells $(\boldsymbol{B})$ and $\mathrm{GCs}$ in the dentate gyrus (DG; $\boldsymbol{C}$. $\boldsymbol{D}, \boldsymbol{D}^{\prime}$, Similarly, (proto-)fibrillar but not monomers/low-molecular-weight oligomers of A $\beta 25-35$ lower the membrane potential threshold for action potential firing in L2/3 pyramidal cells. The arrow points to the steeper slope of the passive membrane charge in the presence of (proto-)fibrillar $A \beta 25-35$ in $V_{\text {ramp }}$ recordings. $E$, Membrane depolarization of $10 \mathrm{mV}$ results in a significant change in pyramidal cell excitability in APdE9 cells. A L2/3 pyramidal cell was held at $-80 \mathrm{mV}$ [corresponding to membrane potential in wild-type mice $(\boldsymbol{B})$ ] or $-70 \mathrm{mV}$ [representative of $A \beta 1$ - 42 effects $(\boldsymbol{B})$ in $A P d E 9$ mice] while stimulating afferent fibers in L1. Note that a $10 \mathrm{mV}$ depolarization converted polysynaptic EPSPs into reliable action potential firing. $\boldsymbol{F}, \boldsymbol{F}^{\prime}$, Fibrillar $A \beta 1-42$ increases network excitability in vitro. The field potential (neuronal population activity) recorded in $L 2 / 3$ in response of $L 1$ stimulation (the arrow indicates remnants of stimulation artifact after subtraction) is larger after acute bath application of fibrillar $A \beta 1-42$ than in control. Both traces are the average of 10 sweeps. ${ }^{*} p<0.05,{ }^{* *} p<0.01$ versus control.

dependent on the genetic background of mice (Carlson et al., 1997), we cannot fully exclude the possibility that sensitization of neuronal networks to overexcitation by $\mathrm{A} \beta$ is not enough to induce generalized seizures without another sensitizing factor such as the PS1 mutation. 


\section{A $\beta$-induced sustained depolarization triggers generalized epilepsy}

Whereas previous studies have suggested a lowered threshold for induced seizures in APP transgenic mice (Del Vecchio et al., 2004; Palop et al., 2007) and morphological changes in hippocampal networks similar to reported after induced seizures (Palop et al., 2007), these studies provided no evidence for mechanisms underscoring increased seizure susceptibility. Instead, consistent with axonal sprouting of excitatory inputs to inhibitory interneurons, Palop et al. (2007) reported enhanced IPSPs in epileptic $A P P$ mouse lines. These network alternations are best explained as compensatory changes counteracting an initial hyperexcitability. Thus, our study extends previous findings toward the initial pathological changes by showing dramatic hyperexcitability of glutamatergic neurons in brain slices of $A P d E 9$ mice and in wildtype mice after preincubation with various fibrillar $\mathrm{A} \beta$ species. Although the preincubation studies were conducted on slices from juvenile rodents (mainly P14-P15), this is unlikely to change the significance of our results, because the most important parameters underlying neuronal excitability (resting potential, intracellular chloride concentration, action potential activation threshold) are already stable at this age (Rheims et al., 2008). Furthermore, A $\beta 25$-35 effects on spike-timing-dependent synaptic potentiation in juveline slices were similar to APdE9 genotype effects in adult animals in our previous study (Shemer et al., 2006). We suggest that the overt excitability in the presence of fibrillar $\mathrm{A} \beta$ is attributable to a dramatic and sustained $V_{\mathrm{R}}$ shift. In support of this notion, a similar change in $V_{\mathrm{R}}$ induced by somatic current injection was a sufficient trigger to generate action potentials in pyramidal cells in response to such extracellular stimulation that normally only evokes polysynaptic EPSPs. Whether this $V_{\mathrm{R}}$ shift is a consequence of an interaction of $\mathrm{A} \beta$ with a specific ion channel, ion transporter or a nonspecific effect on neuronal plasma membranes remains a subject for additional studies.

\section{Clinical significance}

Accumulating evidence indicates that a key event in AD pathology, accumulation of $\mathrm{A} \beta$ in the brain, can itself cause epilepsy at least in transgenic mice. A critical question that remains open is whether a similar mechanism can also account for the increased prevalence of epilepsy in AD patients. Knowing the difficulties in detecting focal limbic seizures with surface EEG and the associated behavioral changes in cognitively impaired individuals with frequent stereotypic movements, one may suspect that epileptic seizures in $\mathrm{AD}$ patients may often escape diagnosis. This notion is a major challenge for the medication of $\mathrm{AD}$ patients, because traditional antiepileptic drugs can further compromise the cognitive performance whereas cholinesterase inhibitors may increase susceptibility to seizures (Babic and Zurak, 1999; Greenberg et al., 2000). If the proposed $A \beta$-induced sustained depolarization proves to be the mechanism of $\mathrm{AD}$-related epilepsy, recordings of $V_{\mathrm{R}}$ in an appropriate cell line may provide a screening tool for the epilepsy promoting versus protecting effects of future candidate AD drugs.

\section{References}

Amatniek JC, Hauser WA, DelCastillo-Castaneda C, Jacobs DM, Marder K, Bell K, Albert M, Brandt J, Stern Y (2006) Incidence and predictors of seizures in patients with Alzheimer's disease. Epilepsia 47:867-872.

Babic T, Zurak N (1999) Convulsions induced by donepezil. J Neurol Neurosurg Psychiatry 66:410.

Breteler MM, Claus JJ, van Duijn CM, Launer LJ, Hofman A (1992) Epidemiology of Alzheimer's disease. Epidemiol Rev 14:59-82.

Busche MA, Eichhoff G, Adelsberger H, Abramowski D, Wiederhold KH,
Haass C, Staufenbiel M, Konnerth A, Garaschuk O (2008) Clusters of hyperactive neurons near amyloid plaques in a mouse model of Alzheimer's disease. Science 321:1686-1689.

Carlson GA, Borchelt DR, Dake A, Turner S, Danielson V, Coffin JD, Eckman C, Meiners J, Nilsen SP, Younkin SG, Hsiao KK (1997) Genetic modification of the phenotypes produced by amyloid precursor protein overexpression in transgenic mice. Hum Mol Genet 611:1951-1959.

Cavazos JE, Golarai G, Sutula TP (1991) Mossy fiber synaptic reorganization induced by kindling: time course of development, progression, and permanence. J Neurosci 11:2795-2803.

Chin J, Palop JJ, Yu GQ, Kojima N, Masliah E, Mucke L (2004) Fyn kinase modulates synaptotoxicity, but not aberrant sprouting, in human amyloid precursor protein transgenic mice. J Neurosci 24:4692-4697.

Del Vecchio RA, Gold LH, Novick SJ, Wong G, Hyde LA (2004) Increased seizure threshold and severity in young transgenic CRND8 mice. Neurosci Lett 367:164-167.

Diez M, Danner S, Frey P, Sommer B, Staufenbiel M, Wiederhold KH, Hökfelt $\mathrm{T}$ (2003) Neuropeptide alterations in the hippocampal formation and cortex of transgenic mice overexpressing b-amyloid precursor protein (APP) with the Swedish double mutation (APP23). Neurobiol Dis 14:579-594.

Fisher RS, van Emde Boas W, Blume W, Elger C, Genton P, Lee P, Engel J Jr (2005) Epileptic seizures and epilepsy: definitions proposed by the International League Against Epilepsy (ILAE) and the International Bureau for Epilepsy (IBE). Epilepsia 46:470-472.

Games D, Adams D, Alessandrini R, Barbour R, Berthelette P, Blackwell C, Carr T, Clemens J, Donaldson T, Gillespie F, Guido T, Hagopian S, Johnson-Wood K, Khan K, Lee M, Leibowitz P, Lieberburg I, Little S, Masliah E, McConlogue L, Montoya-Zavala M, Mucke L, Paganini L, Penniman E, Power M, Schenk D, Seubert P, Snyder B, Soriano F, Tan H, Vitale J, Wadsworth S, Wolozin B, Zhao J (1995) Alzheimer-type neuropathology in transgenic mice overexpressing V717F beta-amyloid precursor protein. Nature 373:523-527.

Garcia-Alloza M, Robbins EM, Zhang-Nunes SX, Purcell SM, Betensky RA, Raju S, Prada C, Greenberg SM, Bacskai BJ, Frosch MP (2006) Characterization of amyloid deposition in the APPswe/PS1dE9 mouse model of Alzheimer disease. Neurobiol Dis 24:516-524.

Götz J, Streffer JR, David D, Schild A, Hoerndli F, Pennanen L, Kurosinski P, Chen F (2004) Transgenic animal models of Alzheimer's disease and related disorders: histopathology, behavior and therapy. Mol Psychiatry 9:664-683.

Greenberg SM, Tennis MK, Brown LB, Gomez-Isla T, Hayden DL, Schoenfeld DA, Walsh KL, Corwin C, Daffner KR, Friedman P, Meadows ME, Sperling RA, Growdon JH (2000) Donepezil therapy in clinical practice: a randomized crossover study. Arch Neurol 57:94-99.

Harkany T, O'Mahony S, Kelly JP, Soos K, Toro I, Penke B, Luiten PG, Nyakas C, Gulya K, Leonard BE (1998) Beta-amyloid(Phe (SO3H)24)25-35 in rat nucleus basalis induces behavioral dysfunctions, impairs learning and memory and disrupts cortical cholinergic innervation. Behav Brain Res 90:133-145.

Hauser WA, Morris ML, Heston LL, Anderson VE (1986) Seizures and myoclonus in patients with Alzheimer's disease. Neurology 36:1226-1230.

Hesdorffer DC, Hauser WA, Annegers JF, Kokmen E, Rocca WA (1996) Dementia and adult-onset unprovoked seizures. Neurology 46:727-730.

Hof PR, Young WG, Bloom FE, Belichenko PV, Celio MR (2000) Comparative cytoarchitechtonic atlas of the C57BL/6 and 129/Sv mouse brains. Amsterdam: Elsevier.

Hsiao KK, Borchelt DR, Olson K, Johannsdottir R, Kitt C, Yunis W, Xu S, Eckman C, Younkin S, Price D, ladecola C, Clark HB, Carlson G (1995) Age-related CNS disorder and early death in transgenic FVB/N mice overexpressing Alzheimer amyloid precursor proteins. Neuron 15:1203-1218.

Jankowsky JL, Fadale DJ, Anderson J, Xu GM, Gonzales V, Jenkins NA, Copeland NG, Lee MK, Younkin LH, Wagner SL, Younkin SG, Borchelt DR (2004) Mutant presenilins specifically elevate the levels of the 42 residue beta-amyloid peptide in vivo: evidence for augmentation of a 42-specific gamma secretase. Hum Mol Genet 13:159-170.

Knobloch M, Farinelli M, Konietzko U, Nitsch RM, Mansuy IM (2007) A $\beta$ oligomermediated long-term potentiation impairment involves protein phosphatase 1-dependent mechanisms. J Neurosci 27:7648-7653.

Kobayashi DT, Chen KS (2005) Behavioral phenotypes of amyloid-based genetically modified mouse models of Alzheimer's disease. Genes Brain Behav 4:173-196. 
Leissring MA, Farris W, Chang AY, Walsh DM, Wu X, Sun X, Frosch MP, Selkoe DJ (2003) Enhanced proteolysis of beta-amyloid in APP transgenic mice prevents plaque formation, secondary pathology, and premature death. Neuron 40:1087-1093.

Lima PA, Vicente MI, Alves FM, Dionisio JC, Costa PF (2008) Insulin increases excitability via a dose-dependent dual inhibition of voltageactivated $\mathrm{K}+$ currents in differentiated N1E-115 neuroblastoma cells. Eur J Neurosci 27:2019-2032.

Lozsadi DA, Larner AJ (2006) Prevalence and causes of seizures at the time of diagnosis of probable Alzheimer's disease. Dement Geriatr Cogn Disord 22:121-124.

Mendez MF, Catanzaro P, Doss RC, Arguello R, Frey WH 2nd (1994) Seizures in Alzheimer's disease: clinicopathologic study. J Geriatr Psychiatry Neurol 7:230-233.

Minkeviciene R, Ihalainen J, Malm T, Matilainen O, Keksa-Goldsteine V, Goldsteins G, Iivonen H, Leguit N, Glennon J, Koistinaho J, Banerjee P, Tanila H (2008) Age-related decrease in stimulated glutamate release and vesicular glutamate transporters in APP/PS1 transgenic and wildtype mice. J Neurochem 105:584-594.

Misonou H, Mohapatra DP, Trimmer JS (2005) Kv2.1: a voltage-gated K+ channel critical to dynamic control of neuronal excitability. NeuroToxicology 26:743-752.

Nissinen J, Lukasiuk K, Pitkänen A (2001) Is mossy fiber sprouting present at the time of the first spontaneous seizures in rat experimental temporal lobe epilepsy? Hippocampus 11:299-310.

Oksman M, Iivonen H, Hogyes E, Amtul Z, Penke B, Leenders I, Broersen L, Lütjohann D, Hartmann T, Tanila H (2006) Impact of different saturated fatty acid, polyunsaturated fatty acid and cholesterol containing diets on beta-amyloid accumulation in APP/PS1 transgenic mice. Neurobiol Dis 23:563-572.

Olafsson E, Ludvigsson P, Gudmundsson G, Hesdorffer D, Kjartansson O, Hauser WA (2005) Incidence of unprovoked seizures and epilepsy in Iceland and assessment of the epilepsy syndrome classification: a prospective study. Lancet Neurol 4:627-634.

Palop JJ, Chin J, Roberson ED, Wang J, Thwin MT, Bien-Ly N, Yoo J, Ho KO, Yu GQ, Kreitzer A, Finkbeiner S, Noebels JL, Mucke L (2007) Aberrant excitatory neuronal activity and compensatory remodeling of inhibitory hippocampal circuits in mouse models of Alzheimer's disease. Neuron 55:697-711.

Plant LD, Webster NJ, Boyle JP, Ramsden M, Freir DB, Peers C, Pearson HA (2006) Amyloid beta peptide as a physiological modulator of neuronal "A"-type $\mathrm{K}^{+}$current. Neurobiol Aging 27:1673-1683.

Price DL, Sisodia SS, Borchelt DR (1998) Genetic neurodegenerative diseases: the human illness and transgenic models. Science 282:1079-1083.
Racine RJ (1972) Modification of seizure activity by electrical stimulation II. Motor seizures. Electroencephalogr Clinl Neurophysiol 32:281-294.

Rheims S, Minlebaev M, Ivanov A, Represa A, Khazipov R, Holmes GL, Ben-Ari Y, Zilberter Y (2008) Excitatory GABA in rodent developing neocortex in vitro. J Neurophysiol 100:609-619.

Shemer I, Holmgren C, Min R, Fülöp L, Zilberter M, Sousa KM, Farkas T, Härtig W, Penke B, Burnashev N, Tanila H, Zilberter Y, Harkany T (2006) Non-fibrillar betaamyloid abates spike-timing-dependent synaptic potentiation at excitatory synapses in layer $2 / 3$ of the neocortex by targeting postsynaptic AMPA receptors. Eur J Neurosci 23:2035-2047.

Sloviter RS (1982) A simplified Timm stain procedure compatible with formaldehyde fixation and routine paraffin embedding of rat brain. Brain Res Bull 8:771-774.

Sorvari H, Soininen H, Pitkänen A (1996) Calbindin-D28Kimmunoreactive cells and fibres in the human amygdaloid complex. Neuroscience 75:421-443.

Szegedi V, Juhász G, Rózsa E, Juhász-Vedres G, Datki Z, Fülöp L, Bozsó Z, Lakatos A, Laczkó I, Farkas T, Kis Z, Tóth G, Soós K, Zarándi M, Budai D, Toldi J, Penke B (2006) Endomorphin-2, an endogenous tetrapeptide, protects against Abeta1-42 in vitro and in vivo. FASEB J 20:1191-1193.

Talley EM, Sirois JE, Lei Q, Bayliss DA (2003) Two-pore-domain (KCNK) potassium channels: dynamic roles in neuronal function. Neuroscientist 9:46-56.

Tauck DL, Nadler JV (1985) Evidence of functional mossy fiber sprouting in hippocampal formation of kainic acid-treated rats. J Neurosci 5:1016-1022.

Tonder N, Kragh J, Bolwig T, Zimmer J (1994) Transient decrease in calbindin immunoreactivity of the rat fascia dentata granule cells after repeated electroconvulsive shocks. Hippocampus 4:79-83.

Tyzio R, Ivanov A, Bernard C, Holmes GL, Ben-Ari Y, Khazipov R (2003) Membrane potential of CA3 hippocampal pyramidal cells during postnatal development. J Neurophysiol 90:2964-2972.

Vezzani A, Sperk G, Colmers WF (1999) Neuropeptide Y: emerging evidence for a functional role in seizure modulation. Trends Neurosci 22:25-30.

Wang Q, Rowan MJ, Anwyl R (2007) $\beta$-Amyloid-mediated inhibition of NMDA receptor-dependent long-term potentiation induction involves activation of microglia and stimulation of inducible nitric oxide synthase and superoxide. J Neurosci 24:6049-6056.

Ye CP, Selkoe DJ, Hartley DM (2003) Protofibrils of amyloid beta-protein inhibit specific $\mathrm{K}^{+}$currents in neocortical cultures. Neurobiol Dis 13:177-190.

Zarándi M, Soós K, Fülöp L, Bozsó Z, Datki Z, Tóth GK, Penke B (2007) Synthesis of Abeta[1-42] and its derivatives with improved efficiency. J Pept Sci 13:94-99. 